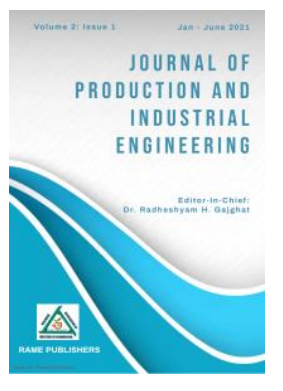

Karthikraj B Tavarageri Corresponding Author kbt.bbt@gmail.com

Department of Mechanical Engineering, Dayananda Sagar Academy of Technology and Management, Bengaluru-560082, India
Journal of Production and Industrial Engineering

Vol. 2, Issue. 1, Feb 2021, pp 19 -25 https://doi.org/10.26706/jpie.2.1.20210102

\section{Fiber-Reinforced Polymer Composites: A Study}

Abstract — The present world demands highly advanced engineering materials with unique mechanical and physical properties for most of the structural applications. Scientists and researchers are working hard to develop multifunctional materials to meet the demands of advanced applications. Matrices and reinforcements are the two major building elements of the composites. While the reinforcements pass on extraordinary materials properties to the composite, the matrix holds the reinforcements in their relative situate firmly. The matrices also protect the reinforcements from the external harm such as environmental, mechanical and chemical damages. Composites are broadly categorized as follows based the type of matrices (polymer, metal, and ceramics) and the geometry of reinforcements (particulate, flake, and fibers). The most widerly used advanced composites in the light weight applications such as aircrafts, spacecrafts, marine and sports equipment's are polymer matrix-based composites (PMC's). Polymers such as epoxy, phenolic and acrylic polyester etc. are used as matrices in the PMC's. The reasons why they are most widely recognized in many applications include their simple processing methods along with their outstanding specific strength and stiffness properties. This work reviews the structure, classification, manufacturing techniques and applications of the currently existing Fiber reinforced polymer.

Keywords - Fiber rein-forced polymer, Manufacturing Techniques, Applications.

\section{INTRODUCTION}

The other name for Fiber reinforced polymer is Fiber reinforced plastic. Fiber reinforced plastics are made from polymer matrix reinforced with fibers. Epoxy vinyl ester (or) polyester, thermosetting plastic are used to make polymers. Aerospace, automotive, marine are the few applications of the fiber rein forced polymer [1]. The definition of the Laminates is, it is the Structural application of Fiber reinforced composites. Stacking a number of thin layers of fibers and matrix are made by laminates [2]. High performance of polymer and composites in the modern era

Review Article - Peer Reviewed

Published online - 22 Feb 2021

(C) 2021 RAME Publishers

This is an open access article under the CC BY 4.0 International License https://creativecommons.org/licenses/by/4.0/

Cite this article - Karthikraj B Tavarageri, "Fiber-Reinforced Polymer Composites: A Study", Journal of Production and Industrial Engineering, RAME Publishers, vol. 2, issue 1, pp. 19-25, 2021. https://doi.org/10.26706/jpie.2.1.20210102 has made to increase the national economy and lifestyle of people in their day-to-day life. In other words, development of FRP when compared to ancient times as been grown rapidly. They even substituted for traditional materials by their advance in the quality and art [3]. The composite is made of two components made of fibers and matrix. The main functions of fibers are providing stiffens, strength high stability, FRP are frequently used to provide initiative and rational solutions to resolve the developing ageing issue in reinforced concrete structural elements [4]. The main purpose pf FRP's are to strengthen, and reinforce structures are normally strong, rated 8 times robust than classical steel reinforced bar. The main purpose of using FRP's is for strengthening rehabilitation and retrofitting has gained move traditional strengthening methods [5]. This paper works furnishes an analysis on fiber reinforced non-polymer composite. As Specified FRP composite is vast topic to completely understand about it. It requires lot of information to write about FRP composites [6]. 


\section{CLASSIFICATION}

Classification of FRP composite material is made on content. They are mainly classified into 3 types i.e., 1) Fiberrein forced composites 2) Particle reinforced composites 3) Sheet module composites.

Figure (1) shows the structure of Classifications of Fiber rein-forced composites. The fiber reinforced composites are made by chemical bonding of cellulosic fiber molecules along with resins in the FRC material matrix using molecular re-engineering process.

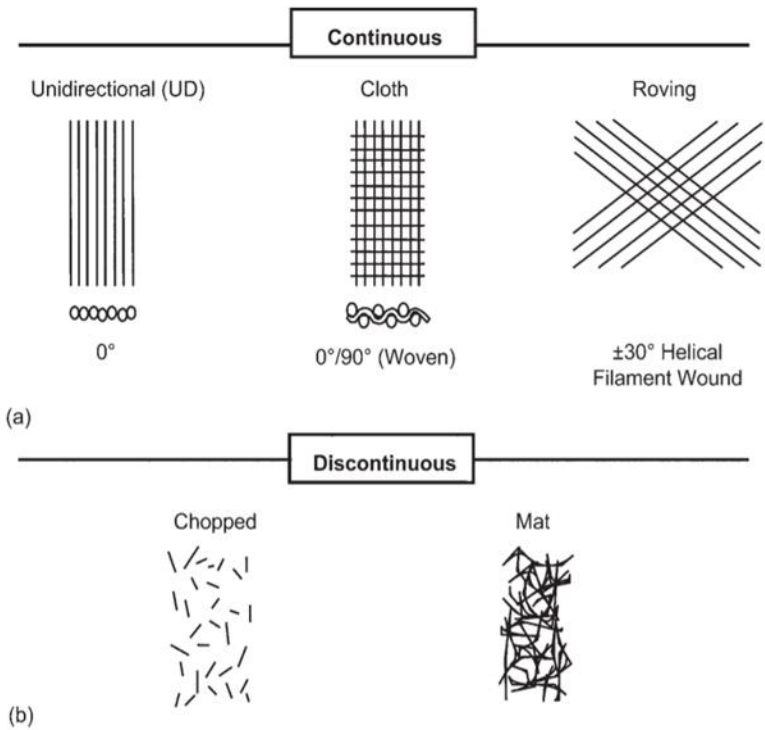

Fig 1: Classifications of Fiber rein-forced composites [7]

Fiber- reinforced composites are classified into two types, continues \& discontinues. continuous are aligned fiber composites. They are processed into the composite tape they are unidirectional and run longitudinally. Discontinuous-fiber composites are arranged random in alignment, which significantly decreases their solidity. The purpose of the discontinuous fiber is they give you isotropic properties, i.e., The direction of the force applied towards mechanical properties will not change. Aligned and Discontinuous are the two parts of the Discontinuous fiber.

Fig (2) shows the particle reinforced arrangement in the composite structure. Particle-reinforced composites are known for Isotropic properties and less cost -effectiveness. These are mainly used for roadways and concrete structures. To obtain the higher mechanical strength Material composites are used. It is a fiber reinforced thermostat material. These are made by combining polymer resin, inert fillers, fiber reinforcement, and stabilizers [7].

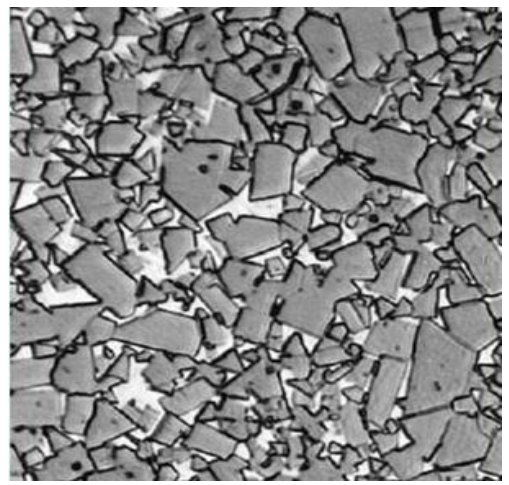

Fig 2: Particle reinforcement arrangement [8]

Sheet molding compounds are the mixture of short chopped fibers, alloy fillers, and liquid thermosetting resin in the form of a bulk material. It is a type of reinforced polyester containing glass (or) carbon fiber. These fibers are usually suspended in the bath of epoxy, vinyl-ester (or) polyester. Sheet molding composites are known for its light weight in nature and more strength than other metal components these are used as primary material for automotive parts [9].

\section{MANUFACTURING TECHNIQUES}

\section{A. Hand lay-up process}

Figure 3 shows the hand-lay fabricating setup for manufacturing of composites. Initially, dry fibers are sewing up or bond fabrics and inserted in mould. By using the brush resin matrix is applied on the reinforcing material. Using of roller to moist composite enhances interaction between the reinforcement and the matrix. Finally, the laminates are kept under standard atmospheric conditions to cure. The main advantages of this process are they are long lasting, wide choice of suppliers and material types. They are rich in fibre contents, and longer fibres [10].

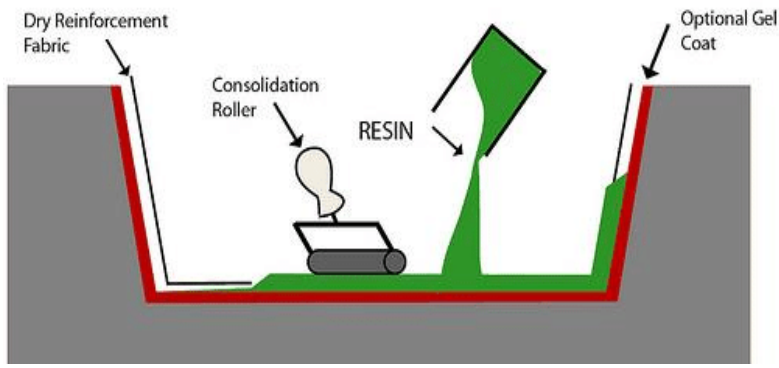

Fig 3: Hand-lay process for fabricating composite materials [11] 


\section{B. Spray up process}

Figure 4 shows the spray-up fabricating setup for manufacturing of composites. This process requires machinist to check the thickness and consistency. The rate of production in Spray up process is slow. This is a process extension of the hand lay-up method. The intense resin and Reinforcement in the form of chopped fibers are sprayed using spray gun. Matrix material and reinforcement are sprayed simultaneously. After the matrix and reinforcement are sprayed, for easy removal of the component a spray gel is applied on the surface Using the roller sprayed material is spread over the surface to remove the air. After showering fiber and resin, curing process is done to the product at required temperatures. Finally, molded part taken out is opened and composite is removed [12].

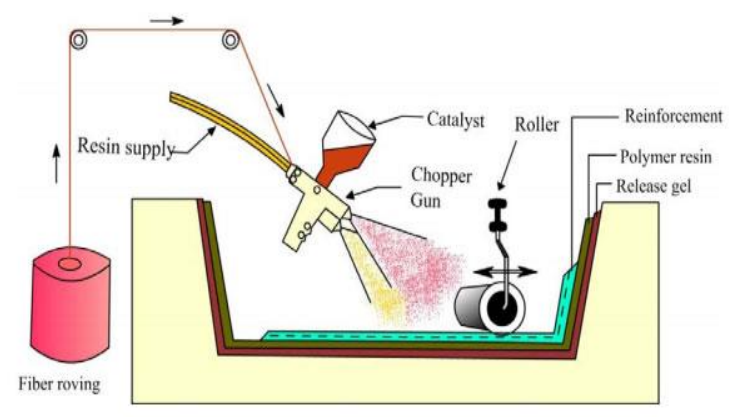

Fig 4: Spray-up process [13]

\section{Vaccum bag moulding process}

Figure 5 shows the vacuum bag fabricating setup for manufacturing of composites. Vacuum bag molding is a modified process of hand lay-up process, a necessarily smaller lay-up is made. All the edges are sealed. In this operation supple film is inserted over the wet layup, and vacuum is removed [14].

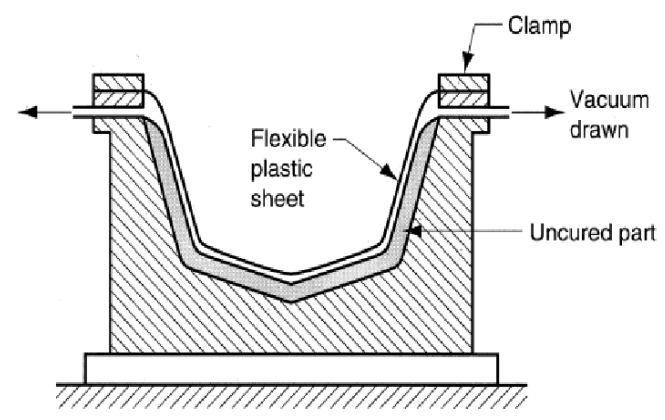

Fig 5: Vaccum bag moulding [15]

\section{Resin transfer moulding}

Figure 6 shows the resin transfer fabricating setup for manufacturing of composites. resin transfer moulding makes use of liquid regulator resin to souse a fiber placed in a closed mold. This moulding process will be done in closed area. The other name for resin transfer moulding is Liquid transfer moulding process. Glass fibers, carbon fibers, natural plant fibers, aramid fiber are the reinforcing fibers. In this process there are two separate containers. Resin and catalyst are separated in separate containers. Resin and catalyst both are mixed in mixing chamber. This process can be done in two parts i.e., upper half and lower half. Heating process blended with molding unit. During clamping process vents are used to release the gases from the mold. Finally, end product is obtained by opening the mould. This process doesn't require high injection pressure [16].

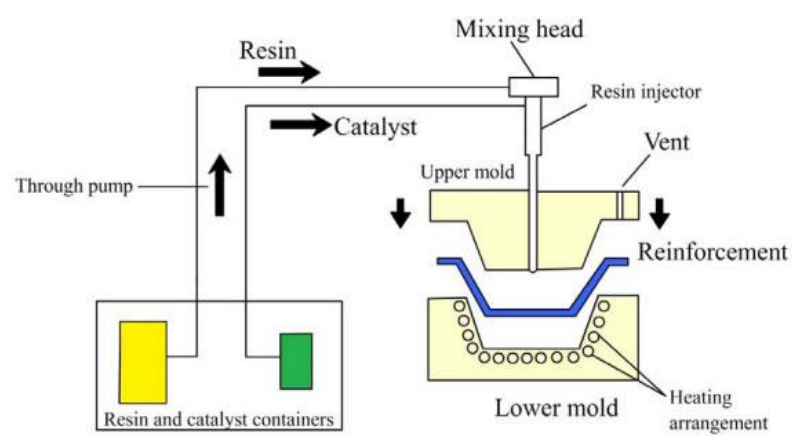

Fig 6: Resin transfer moulding [17]

\section{E. Vaccum infusion process}

Figure 7 shows the vaccum infusion fabricating setup for manufacturing of composites. The main advantage of this process is, it uses atmospheric pressure to push the resin into cavity. In vaccum infusion process voids are filled the porous material fluid resin.

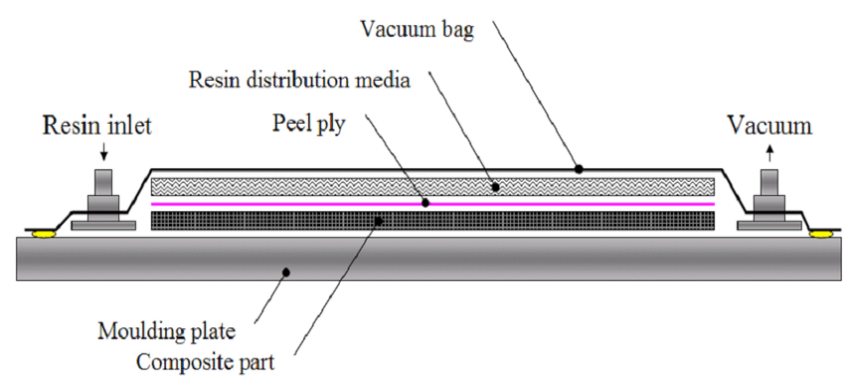

Fig 7: Vaccum infusion process [18] 
This resin hardens, the resin matrix combines the materials into a rigid composite. Organic materials such as flax or other fibers and inorganic fibers are the typical materials used. Vacuum infusion process provides better fiber to resin ratio and also wastage of resin is also less. Usage of resin is very consistent [19].

\section{F. Compression moulding process}

Fig 8 shows the compression moulding fabricating setup for manufacturing of composites. In this process hydraulic force is used to compress and Pneumatic is used to shape the materials. Raw material is kept for heating in the closed condition for the required amount of time. Flashing process is done to removal of excess materials. To maintain the exact measurement of the product manufactured flashing is removed [21].

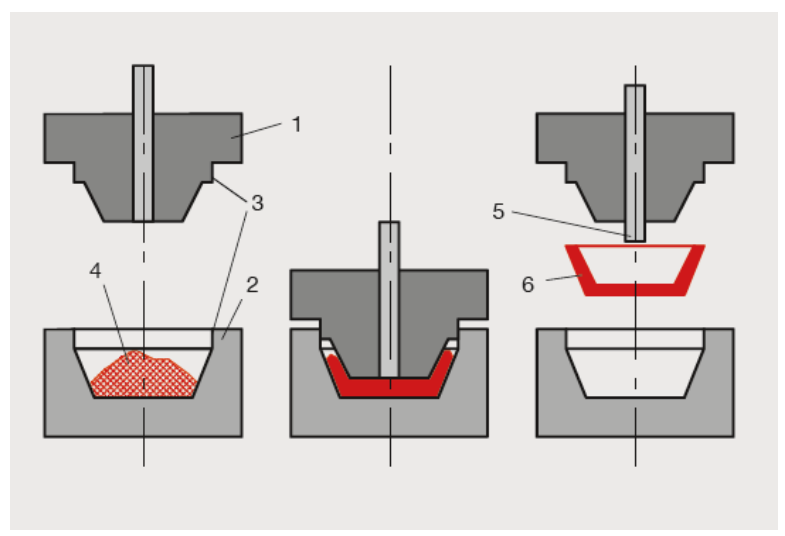

Fig 8: Compression moulding process [20]

\section{G. Pultrusion}

Figure 9 shows the pultrusion fabricating setup for manufacturing of composites. Initially, process is done by the support of reinforcements. The material is feed into the infeed area where it can be made according to the required shape. Impregnated reinforcement will be removed from the infeed area to heated pultrusion die.

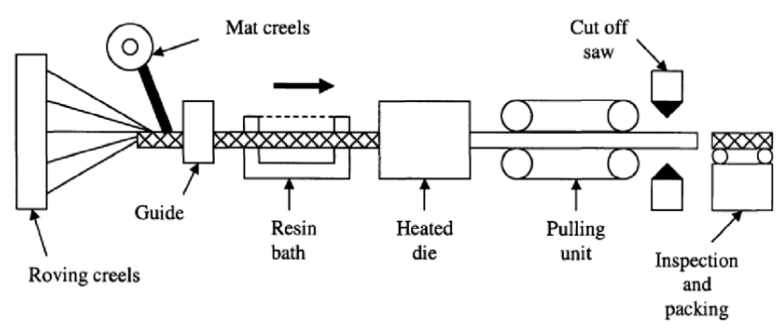

Fig 9: Pultrusion process [21]
The resin matrix solidifies the impregnated reinforcement. Then it is allowed to cool before being clamped by the reciprocating puller units. The profile passes through the cut off saw. In cut off saw it is cut to the required shape [22].

\section{H. Electrospinning process}

Fig 10 shows the electrospinning fabricating setup for manufacturing of composites. This process uses electric force to attract charged threads of polymer solutions. When high voltage current is supplied to liquid droplets it becomes charged. At a censorious point liquid breaks down from the surface. This point of breakdown is called as Taylor cone. Liquid jet is formed when cohesion between molecules is strong and when stream breakup doesn't occur. The elongation of the jet is made by a whipping process. This causes electrostatic disgust starts at tiny bends and deposited at the ground [23].

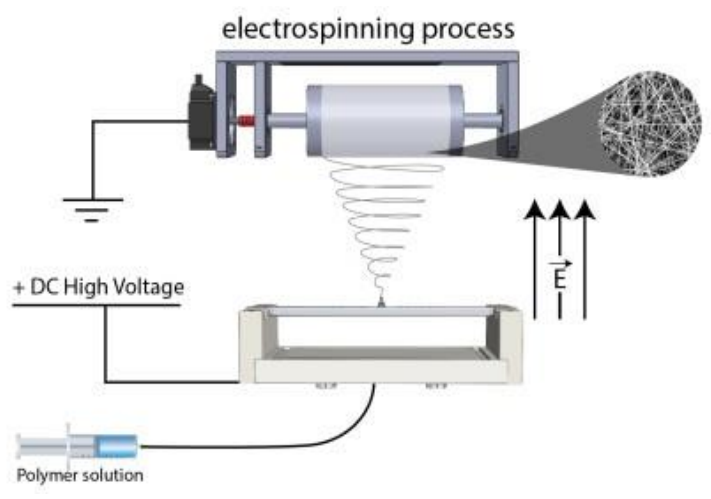

Fig 10: Electrospinning process [23]

\section{Filament winding}

Figure 11 shows the filament winding fabricating setup for manufacturing of composites. Filament winding is a precision high speed positioning process of long fiber in a pre-determined design. This process involves two components i.e., steel mandrel and carriage arm. The function of the steel mandrel is to rotate and the function of the carriage arm is to move horizontal and vertical direction. The carriage arm includes eye which groups roving. The fibers are impregnated in resin before encountering the mandrel. After sometime these later will solidify to make final composite material [24]. 


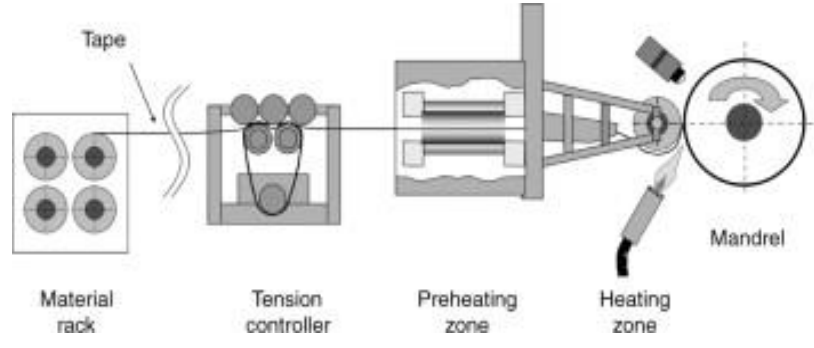

Fig 11: Filament winding [25]

\section{APPLICATIONS}

Figure 12 shows the bridge construction fabricating setup for manufacturing of composites. FRP composites plays an important role in civil engineering applications as they are having high strength, high stiffness and they can withstand high weight ratios, they are highly corrosive resist in nature.

They possess high durability strength towards the materials and they are light weight in nature. They are majorly used to renovate the old structures, viaduct, conduit. In modern times, they are mainly used for concrete buildings, due to their high tailorable characteristic in nature. These are having low life cycle cost. These modernized FRP structures have made development in the constructional concepts [26].

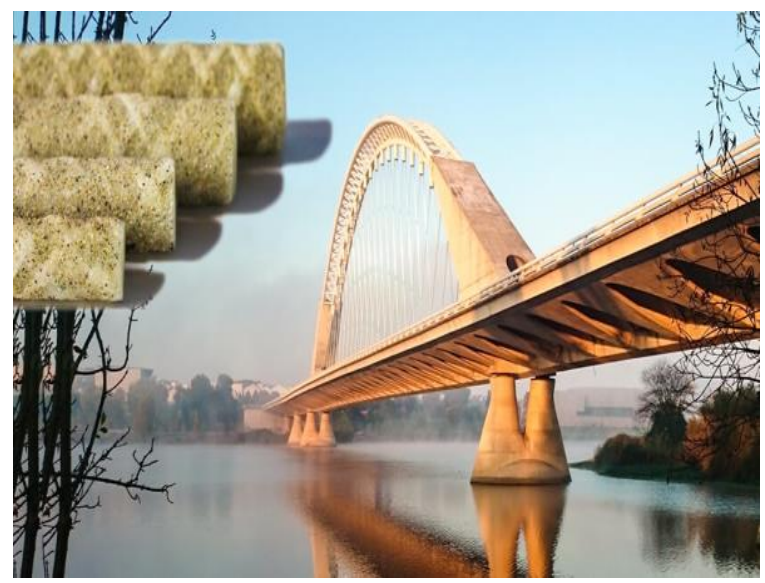

Fig 12: Bridge construction using FRP composite [27]

Figure 13 shows the Disc brake fabricating setup for manufacturing of composites. In automobile braking systems, Temperature can reach upto Thousands of centigrade. Brakedown of chances is more in case use of other materials. Therfore Using carbon fiber-reinforced silicon carbide for Braking materials withstans high tempetraure and finds application for Heavy materials, i.e., in High speed bullet train and also mainly used for emergency brakes in all the heavy vehicles.

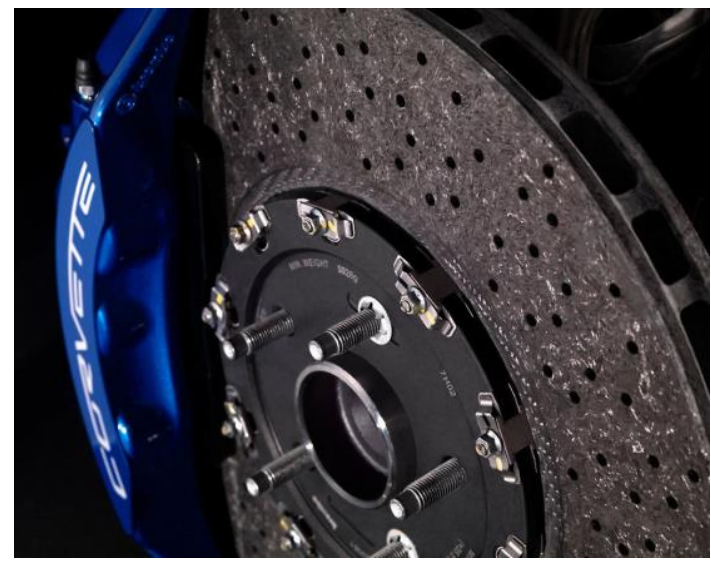

Fig 13: Disc brake made from FRP [28]

Other application of FRP composite can be found in Enginehood,dash+boards, \& storagetanks are made by using of natural fibers. Using these fibers decreases the weight of the material and enhances in stability and strength of the material [29].

\section{A. Aerospace}

Fig 14 shows the use of FRP in aerospace fabricating setup for manufacturing of composites. In the beginning, composites materials were only for secondary parts. But in modern days these FRP's replaced primary structures. Examples for primary structures are wings and fuselages. In commercial aircraft it is better to use composite materials as it reduces the airframe weight. This reducing the airframe rate can be used to store extra fuel. In inclusion to the flexibility to make advancement in the Geometry. The creator makes composites to increase material strength or stiffness to meet the local loading [30].

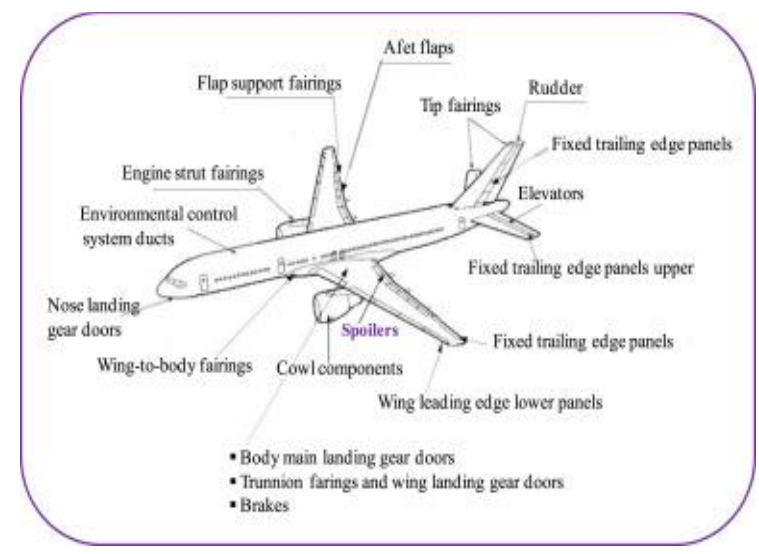

Fig 14: Uses of FRP in aeropsace [31] 


\section{B. Marine}

The introduction of composite materials in marine structures has made a breakthrough change in the building of boats, ships \& submarines. Composite automation has made improving the standard of products. By increasing the quality of the product, makes the materials lighter in structures and also their buoyancy will increase. The skin with high stiffness provides more stiffness quality to the product. meanwhile, core supports shear and other stresses to make higher standard product that makes skin stabilizing and prevent local and global instabilities. Reducing the weight has more advantages as this reduction will be useful for larger spacious, fuel-saving, lower inertia, and buoyancy. Instead of metals commonly used skins are aramid, carbon and glass FRP. For core material polystyrene and polyvinyl chloride are mainly used. Example for longest ship built from FRP is corvettes [30].

\section{Challenges}

In fabricating FRC material the major challenge is they are in need of fiber-matrix characterization perception. This lack of the fiber matrix affects the final properties of material. The rate of manufacturing always affects the cost of manufacturing-For the cost-effective manufacturing production rate should be high. From last few years, there has been a lot of research has been done on the FRP materials on their strength and other mechanical properties. This research has bought advancement in mechanisms in debonding failures. Continuous research on the strength based debonding problems has achieved to overcome the solution with several methods that predict bonding stress distributions on assuming that all materials are having high elastic strength [29].

\section{CONCLUSIONS}

Fiber-reinforced polymer-based composites are a class of advanced engineering materials exhibiting excellent mechanical properties even compared to most of the metallic materials available for structural applications. In most of the advanced structural applications FRP's are widely used and replacement of which is considered as highly unrealistic. As a part of development, scientists and researchers are bringing out advanced FRP composites to suit applications. Recent advances in the field of science and technology have motivated the people working in the field of composites for further research to develop multi-functional FRP composites for advanced structural applications. In the past few decades, few authors have demonstrated the potential improvement in the properties and performances of polymer-based composites. Most of the structural applications (such as structural components of aircrafts, spacecrafts, automobiles electronic equipment's, medical equipment's and even sporting goods) demand fiber reinforced composites due to their excellent mechanical and physical properties. These needs have motivated the people working in field of composites to upgrade these fiber reinforced composites with enhanced potential to suit multiple requirements in advanced applications.

\section{REFERENCES}

[1] Alberto M. Introduction of Fibre-Reinforced Polymers Polymers and Composites: Concepts, Properties and Processes. Fiber Reinf. Polym. - Technol. Appl. Concr. Repair, InTech; 2013. https://doi.org/10.5772/54629.

[2] King RL. Fibre-reinforced composites materials, manufacturing and design. vol. 20. 1989. https://doi.org/10.1016/0010-4361(89)90651-4.

[3] Polymer Matrix Composites and Technology | ScienceDirect n.d.

https://www.sciencedirect.com/book/9780857092212/polym er-matrix-composites-and-technology (accessed February 21, 2021).

[4] Sonnenschein R, Gajdosova K, Holly I. FRP Composites and their Using in the Construction of Bridges. Procedia Eng 2016;161:477-82. https://doi.org/10.1016/j.proeng.2016.08.665.

[5] Mugahed Amran YH, Alyousef R, Rashid RSM, Alabduljabbar H, Hung CC. Properties and applications of FRP in strengthening RC structures: A review. Structures 2018;16:208-38. https://doi.org/10.1016/j.istruc.2018.09.008.

[6] Panchagnula KK, Palaniyandi K. Drilling on fiber reinforced polymer/nanopolymer composite laminates: A review. J 
Mater Res $\quad$ Technol 2018;7:180-9. https://doi.org/10.1016/j.jmrt.2017.06.003.

[7] Campbell F. Structural Composite Materials. ASM International. 2010:612.

[8] Tensile Strength of Composits n.d.

[9] Orgéas L, Dumont PJJ. Sheet Molding Compounds. Wiley Encycl. Compos., Hoboken, NJ, USA: John Wiley \& Sons, Inc.; 2012, p. $\quad$ 1-36. https://doi.org/10.1002/9781118097298.weoc222.

[10] Zweben C. Composite Materials. Mech Eng Handb Mater Mech Des Third Ed 2006;1:380-417. https://doi.org/10.1002/0471777447.ch10.

[11] Udupi SR, Lester Raj Rodrigues L. Detecting Safety Zone Drill Process Parameters for Uncoated HSS Twist Drill in Machining GFRP Composites by Integrating Wear Rate and Wear Transition Mapping. Indian J Mater Sci 2016;2016:1-8. https://doi.org/10.1155/2016/9380583.

[12] Mazumdar S. Composites Manufacturing. Compos Manuf 2001. https://doi.org/10.1201/9781420041989.

[13] Manufacturing Products for Spray-up Process n.d. https://www.eppcomposites.com/spray-layup-process.html (accessed February 21, 2021).

[14] Tiwari N. Introduction to Composite Materials and Structures Lecture Notes, IIT Kanpur 2015.

[15] Bs H, Gmn I, Anma H. Advance Research in Textile Engineering Applications of Nanotechnology in Textiles : A Review 2019;4:1-9.

[16] Lin MY, Murphy MJ, Hahn HT. Resin transfer molding process optimization. Compos Part A Appl Sci Manuf 2000;31:361-71. https://doi.org/10.1016/S1359835X(99)00054-8.

[17] Manufacturing Products for RTM Process n.d. https://www.eppcomposites.com/rtm-process.html (accessed February 21, 2021).

[18] Abdurohman K, Siahaan M. Effect of mesh-peel ply variation on mechanical properties of E-glas composite by infusion vacuum method. J Phys Conf Ser 2018;1005. https://doi.org/10.1088/1742-6596/1005/1/012009.

[19] Modi D, Correia N, Johnson M, Long A, Rudd C, Robitaille F. Active control of the vacuum infusion process. Compos
Part A Appl Sci Manuf 2007;38:1271-87. https://doi.org/10.1016/j.compositesa.2006.11.012.

[20] Thermoset Compression Moulding | aarePlast n.d. https://www.aareplast.ch/en/thermoset-processes/thermosetcompression-moulding (accessed February 21, 2021).

[21] Madiwale. Compression moulding | Compression moulding process 2019:1615-24.

[22] Polymer FR. عملكرد ميانقاب هاي تقويت شده باورقه هاب FRP ( Fiber Reinforced Polymer ) n.d.

[23] Park JS. Electrospinning and its applications. Adv Nat Sci Nanosci Nanotechnol 2010;1:5. https://doi.org/10.1088/20436262/1/4/043002.

[24] FRP Composites And Bridge Design Objectives | TUF-BAR n.d. https://www.tuf-bar.com/frp-composites-and-bridgedesign-objectives/ (accessed February 21, 2021).

[25] Quanjin M, Rejab MRM, Kaige J, Idris MS, Harith MN. Filament winding technique, experiment and simulation analysis on tubular structure. IOP Conf Ser Mater Sci Eng 2018;342. https://doi.org/10.1088/1757-899X/342/1/012029.

[26] Superbrakes for Civilians? The Cost Is the Obstacle - The New York Times n.d. https://www.nytimes.com/2010/08/01/automobiles/01BRAK ES.html (accessed February 21, 2021).

[27] Zyjewski A, Chróścielewski J, Pyrzowski Ł. The use of fibrereinforced polymers (FRP) in bridges as a favourable solution for the environment. E3S Web Conf 2017;17. https://doi.org/10.1051/e3sconf/20171700102.

[28] Rajak DK, Pagar DD, Menezes PL, Linul E. Fiber-reinforced polymer composites: Manufacturing, properties, and applications. Polymers (Basel) 2019;11. https://doi.org/10.3390/polym11101667.

[29] Guermazi N, Ben Tarjem A, Ksouri I, Ayedi HF. On the durability of FRP composites for aircraft structures in hygrothermal conditioning. Compos Part B Eng 2013;85:294304. https://doi.org/10.1016/j.compositesb.2015.09.035.

[30] Galbraith JA, Simpson Gumpertz PE, Heger I. Use of FRP to Strengthen and Repair Marine Structures 2016.

[31] Sreenivasulu R. Aero Space Applications of GFRP Composites: Review'. Int J Mech Eng Res 2013;3:10-4. 